\title{
DIÁLOGO ENTRE OS ESTUDOS PÓS-COLONIAIS E O FEMINISMO LATINO-AMERICANO NA COMPREENSÃO DO PATRIARCADO NA CONSTITUIÇÃO DA AMÉRICA LATINA ${ }^{\mathbf{1}}$
}

Dialogue between post-colonial studies and latin american feminism in the understanding of patriarchy in the constitution of Latin America

SANTOS, Aline Renata dos 2 SILVA, Janssen Felipe da ${ }^{3}$

\begin{abstract}
Resumo: 0 artigo realiza um diálogo entre os Estudos Pós-coloniais (Grosfoguel, 2008; Mignolo, 2011; Quijano, 2005) e o Feminismo Latino-americano (Lugones, 2008; Paredes, 2011; Saffioti, 2015) para analisar o patriarcado como elemento constitutivo da América Latina, que sobrevive através das heranças coloniais, e compreender os novos desafios de luta e mobilização política de enfrentamento ao patriarcado. Este diálogo é relevante uma vez que as heranças coloniais que assolam às mulheres têm o seu cerne no patriarcado colonialmoderno, que impôs às mulheres da Abya Yala ${ }^{4}$ e da África à condição de não sujeitos. Essa imposição consolidou um modelo de organização político-social referenciado no homembranco-heterossexual-patriarcal-cristão. Tal organização não só estabeleceu um modo de ser mulher, como também gerou hierarquias intragênero que possuem como termômetro os marcadores de raça-etnia, classe social, território, sexualidade que ao se interseccionarem intensificam às subalternizações.
\end{abstract}

Palavras-chave: Patriarcado. Estudos Pós-coloniais. Feminismo Latino-americano

\begin{abstract}
This article accomplishes a dialogue between the Post-Colonial Studies (Grosfoguel, 2008; Mignolo, 2011; Quijano, 2005) and the Latin American Feminism (Lugones, 2008; Paredes, 2011; Saffioti, 2015) intending to analyze the patriarchy as a constitutive element of Latin America, that survives through colonials heritages, and to comprehend the new fight challenges and political mobilization against patriarchy. This dialogue is relevant since the colonials heritages that ravage the women have their core from the modern colonial patriarchy, which imposed the Abya Yala and Africa women to the non-subject condition. This imposition consolidated a model of social political organization referenced in the patriarchalheterosexual-white-christian man. Such organization didn't only established a way of how to be a woman, but also generated intragender hierarchies that have as a thermometer the markers of race- ethnicity, social class, territory, sexuality, that once they have an intersection they intensify the subalternations.
\end{abstract}

Keywords: Patriarchy. Post-Colonials Studies. Latin American Feminism.

\footnotetext{
${ }^{1}$ Recebido em: 14 mai. 2018. Aceito em: 18 set. 2018.

2 Mestra em Educação pela Universidade Federal de Pernambuco. Doutoranda do Programa de Pósgraduação em Educação da Universidade Federal de Pernambuco. Professora substituta do curso de pedagogia da Universidade Federal de Pernambuco Campus Agreste. E-mail: aline.renata24@hotmail.com 3 Doutor em Educação pela Universidade Federal de Pernambuco. Professor associado do curso de pedagogia da Universidade Federal de Pernambuco Campus Agreste. E-mail: janssenfelipe@hotmail.com 4 Segundo Porto-Gonçalves (2009, p. 25), "significa Terra em florescimento e é sinônimo de América".
} 


\section{Introdução}

Este artigo articula os Estudos Pós-coloniais e o Feminismo Latino-americano como uma das possibilidades de interpretar o patriarcado como elemento constitutivo da América Latina e de compreender os novos desafios de luta e mobilização política de enfrentamento ao patriarcado 5 . A nosso ver, estes novos desafios são velhos com roupagem nova, pois desde o processo de colonialismo os povos da Abya Yala/América Latina lutam por liberdade das amarras imperialistas que ainda tornam os diferentes em desiguais. Partimos dessa compreensão para realizar um diálogo político-epistemológico entre os Estudos Pós-coloniais e o Feminismo Latino-americano, objetivando desvelar as heranças coloniais, que possuem como um dos seus pilares o patriarcado, e evidenciar proposições no combate a estas heranças. Este diálogo se faz importante uma vez que o patriarcado se encontra no cerne das hierarquias de gênero, de raça-etnia, de sexualidade, dentre outras, que foram impostas aos povos da América Latina e que ainda sobrevivem. Cabe destacar que as hierarquias supracitadas são tensionadas constantemente por diferentes sujeitos que lutam por uma sociedade que tenha por base à justiça social.

Entendemos que os Estudos Pós-coloniais e o Feminismo Latino-americano fazem partem de um movimento político-epistemológico global que se inicia no sul global no esforço de questionamento, resistência e proposição em relação ao paradigma dominante (Santos, 2003). Na nossa compreensão, os Estudos Pós-coloniais e o Feminismo Latinoamericano são parte dos paradigmas emergentes, ou melhor dizendo, anti-imperialistas. Segundo Santos (2003), tais paradigmas intencionam religar as conexões que foram rompidas com o paradigma dominante e propõem formas outras de produção de conhecimento que não afastem os sujeitos de suas práticas. Reconhecemos que estamos dentro de movimentos que se complementam e se relacionam mutuamente, estas formas outras de olhar a realidade pretendem romper com as hierarquias que justifica/naturaliza as desigualdades de classe, de gênero, de raça, de território, entre outras.

Transgredir as hierarquias, impostas aos povos da América Latina, em especial às mulheres, perpassa por um duplo movimento: a desnaturalização das hierarquias e a

\footnotetext{
${ }^{5}$ Este artigo é um recorte da abordagem teórico-metodológica de uma pesquisa de doutorado em educação que está em desenvolvimento.
} 
construção de práticas que articulem a construção teórica e a ação política social. Chamamos a atenção que os Estudos Pós-coloniais e o Feminismo Latino-americano realizam esse duplo movimento. Os Estudos Pós-Coloniais desafiam as estruturas modernas de poder e de produção de conhecimento, colocam em xeque a razão moderna/eurocêntrica, a versão eurocêntrica de história, como também a herança colonial. Estes Estudos, de acordo com Silva (2015, p. 49), "emanam do ideário e das práticas sociopolíticas epistêmicas dos povos indígenas e afrodescendentes desse continente em profundo diálogo com os movimentos de descolonização das demais partes do mundo". E o Feminismo Latino-americano vem realizando rachaduras políticas e epistêmicas ao denunciar as formas de exploração e opressão sofridas pelas mulheres indígenas, negras e mestiças pobres da Abya Yala. 0 revide epistêmico e político do Feminismo Latino-americano questiona a ego-corpo-política do conhecimento (Grosfoguel, 2008) fundada no conhecimento científico-eurocêntrico-moderno-brancomasculino-heterossexual-cristão-patriarcal.

O Feminismo Latino-americano compreende que a ego-corpo-política do conhecimento está na base do processo de colonialismo da América Latina, tendo em vista que as práticas cotidianas estiveram pautadas em um modo de produção e reprodução da vida nos moldes patriarcais que gestaram novas formas de dominação e exploração entre europeus, povos originários e os negros escravizados. Estas relações desiguais entrelaçaram-se na maximização da dominação e exploração dos povos, pois as diferenças que os constituíam foram classificadas e hierarquizadas tomando por referência a cosmovisão brancocêntrica. Aqueles e aquelas que mais se distanciavam dessa referência sofriam/sofrem de modo mais visível e violento as desigualdades balizadas na ideia de superioridade e inferioridade de raças-etnias, sexos-gêneros, territórios. Estas hierarquias permanecem na atualidade como podemos observar nos dados do IBGE/PNAD ${ }^{6}$ ao demonstrarem que mulheres não brancas ocupam os trabalhos de menor prestígio social, em condições insalubres e com salários inferiores, que possuem os menores índices de escolarização.

Na intenção de desvelar o patriarcado enquanto um dos pilares constitutivos dos processos de subalternizações que foram impostos aos povos originários da América-

${ }^{6}$ Instituto Brasileiro de Geografia e Estatística e Pesquisa Nacional por Amostra de Domicílios (2015). 
latina e mais tarde aos povos advindos da África, organizamos este texto em três seções, a saber: 1) o patriarcado colonial-moderno; 2) o processo de colonialismo e a instauração das hierarquias e subalternizações alicerçadas no patriarcado colonial-moderno: uma visão dos Estudos Pós-coloniais e do Feminismo Latino-americano; 3) conclusões.

\section{Patriarcado Colonial/Moderno}

No intuito de discorrer sobre o patriarcado colonial-moderno se faz necessário retomar o conceito de família, em especial, a família patriarcal. Esta discussão é relevante para apreendermos como o referido patriarcado se instaurou nas terras da Abya Yala com o processo de colonialismo-colonização e como permanece na contemporaneidade.

O entendimento de família hegemônica que temos atualmente foi resultado de transformações sociais, culturais e políticas ocorridas durante a história. Estas transformações aconteceram de formas distintas, não havia um modelo de organização social único. De acordo com Narvaz e Koller,

família não é algo biológico, algo natural ou dado, mas produto de formas
históricas de organização entre os humanos. Premidos pelas
necessidades materiais de sobrevivência e de reprodução da espécie, os
humanos inventaram diferentes formas de relação com a natureza e entre
si (2006, p. 49-50).

Nessa linha de raciocínio, podemos afirmar que família é uma invenção social, cultural, histórica e política, que se configurou/configura de distintas maneiras a depender das necessidades dos grupos de humanos em dado contexto sócio-histórico. Uma das formas de constituição familiar é a família patriarcal, que se estabeleceu como o padrão ideal de família, principalmente, nas colônias portuguesas e espanholas instauradas nas terras da Abya Yala.

Narvaz e Koller (2006) realçam que o termo família vem do latim famulus que significa escravo doméstico, coadjuvantes. 0 pai possuía poder sobre a vida e a morte da mulher, das filhas e dos filhos, das escarvas e dos escravos. Com a invasão das terras da Abya Yala este modelo de organização familiar de poder foi imposto aos povos originários e posteriormente aos povos oriundos da diáspora africana. Este processo de organização 
familiar foi e é fundamental para instauração e manutenção das relações de poder desiguais neste continente.

Philippe Ariès (1986) sublinha que as primeiras imagens de famílias passam a ser retratadas na iconografia medieval por volta do século XVI. As iconografias, inicialmente, apresentavam imagens de homens ligadas ao ofício, com o passar do tempo foram sendo acrescidas imagens de mulheres e de crianças. Ele aponta que as primeiras iconografias retrataram cenas cotidianas familiares.

A esse respeito, Ariès descreve fragmentos de um calendário datado do início da segunda metade do século XVI, nele é ilustrada uma cena familiar em que as personagens do pai e da mãe ocupam a centralidade da imagem. 0 pai segura a mão do filho e a mãe a mão da filha, os criados homens estão ao lado do pai e as criadas mulheres estão ao lado da mãe. 0 autor revela que nessas primeiras iconografias a separação entre os sexos.

Em continuidade com sua análise, Ariès (1986) salienta que as iconografias que antes ilustravam cenas ligadas ao espaço público passam a ilustrar cenas da vida privada. Para o autor, essa não é uma simples mudança, mas representa a criação do sentimento da família. Assim, as cenas familiares com o decorrer dos tempos passaram a não só ilustrar a imagem da família, bem como ocorreram em dizer dos papéis de gênero atribuídos a cada membro da família. As imagens que retratavam o sentimento da família também denotaram os papéis sociais ordenados por meio do sexo-gênero. Estas imagens de família e de sentimentos ainda continuam, a nosso ver, como heranças herdadas com o processo de colonialismo e colonização no processo de constituição da sociedade moderna-patriarcal-cristã-eurocêntrica, em especial, na América Latina.

Ressaltamos que houve/há famílias que fogem a este padrão centrado na autoridade masculina. Durante a história houve modelos de famílias chefiados por mulheres centradas na descendência feminina (Narvaz; Koller, 2006). No entanto, estas teóricas que nunca houve um período histórico matriarcal em que as mulheres fossem, de fato, o gênero dominante, ou seja, mesmo quando as famílias fossem chefiadas por mulheres, estas não possuíam domínio sobre os homens. Delgado e Franco (2014, p. 97) frisam que "lo que sí existieron, fueron sociedades donde las mujeres disfrutaron mayores niveles de igualdad sustantiva frente a los hombres, en la cual la posición de la mujer era 
más respetada y valorada". Na organização social dos grupos, as mulheres tinham um papel importante na reprodução da espécie e como guardiãs da descendência.

Narvaz e Koller enfatizam que "os papéis sexuais e sociais de homens e de mulheres não eram definidos de forma rígida e as relações sexuais não eram monogâmicas, tendo sido encontradas tribos nas quais as relações entre homens e mulheres eram bastante igualitárias" (2006, p. 50). Este cenário modifica-se a partir do advento da propriedade privada, no qual os homens passam a interferir na reprodução da espécie para garantir a descendência e os herdeiros legítimos. Simone de Beauvoir (1970, p. 75) aponta que

o direito paterno substituiu-se então ao direito materno; a transmissão da propriedade faz-se de pai a filho e não mais da mulher a seu clã. É o aparecimento da família patriarcal baseada na propriedade privada. Nessa família a mulher é oprimida. 0 homem, reinando soberanamente, permite-se, entre outros, o capricho sexual: dorme com escravas ou hetairas, é polígamo.

Nas palavras da autora, observamos o surgimento da preponderância masculina, que não foi de repente, mas com um longo processo, resultou que o trabalho do homem se torna fundamental e o da mulher insignificante. Destas transformações decorreu a necessidade do estabelecimento da monogamia como forma de garantir a herança aos filhos legítimos. E para que a descendência legítima fosse garantida

o corpo e a sexualidade das mulheres passou a ser controlado, instituindo-se então a família monogâmica, a divisão sexual e social do trabalho entre homens e mulheres. Instaura-se, assim, o patriarcado, uma nova ordem social centrada na descendência patrilinear e no controle dos homens sobre as mulheres (Narvaz; Koller, 2006, p. 50).

Ressaltamos que estas mudanças não ocorreram de forma linear e simultânea em todos os lugares. Por exemplo, no território da Abya Yala coexistiam distintas formas de organização social entre os povos antes da invasão portuguesa e espanhola. Em conformidade com a cultura de cada povo havia relações desiguais entre sexo-gênero, como também povos em que havia uma relação de complementariedade e independência ${ }^{7}$ entre o feminino e o masculino. Delgado e Franco assinalam que

\footnotetext{
${ }^{7}$ A exemplo dos índios Comuneros de Ccollquepata (situada na região de Cusco, Peru) que eram governados por uma mulher, Dona Martina da Paz Chiguantupa, que devido à colonização teve seus poderes enfraquecidos, bem como o de outras mulheres, pois não era permitido que a mesma nomeasse outra mulher para dividir o seu governo sem que seu marido permitisse (SILVERBLATT, 1990).
} 
la América pre-colombina era un mundo totalmente sexo-diverso, con diferentes grados de igualdad y equidad de género. Estructuras patriarcales y heteronormativas hacen su presencia en algunos pueblos originarios, pero como observaremos más adelante, serán afianzadas con la introducción de la civilización europea cristiana (2014, p. 99).

0 modelo de família patriarcal foi transposto aos povos da Abya Yala através da herança cultural, produto da união da cultura misógina greco-latina e da cultura misógina judaico-cristã, herdadas pelos espanhóis e portugueses. Delgado e Franco (2014, p. 104) ressaltam que "la familia y el matrimonio constituyeron dos instituciones fundamentales de la colonización europea, ya que a través de ellas el Estado Monárquico y la Iglesia Católica, preservaban el orden establecido, la sociedad estamental trasplantada a este continente".

No período colonial, no Brasil, a base organizativa da sociedade foi, predominantemente, a família patriarcal em que o pai (senhor do engenho) tinha poder sobre a sua mulher, filhos e escravos. E desenvolveu-se uma sociedade organizada por meio da exploração e do controle dos corpos de mulheres (brancas, índias, negras e mestiças), do trabalho escravo, inicialmente, dos povos originários e, posteriormente, com o sequestro dos povos da diáspora africana. Paredes ratifica que

la sucesión de la historia nos muestra que los cuerpos primeramente doble y triplemente oprimidos son los de todas las mujeres. La humanidad aprendió a oprimir explotar, discriminar, oprimir, dominar en el cuerpo de las mujeres y de ahí se fue desarrollando hasta tener hoy en día un sistema súper bien afinado, es a este sistema que nosotras le llamamos Patriarcado (2011, p. 4).

Assinalamos que o patriarcado não está restrito apenas ao modelo de família patriarcal, visto que ele atravessa a sociedade como um todo (Saffioti, 2015). Nesse sentido, o patriarcado atualmente não assinala apenas a autoridade do pai sobre a família e sim o poder do homem/masculino ${ }^{8}$ sobre a mulher/feminino. A junção entre os patriarcados originários e o patriarcado advindo dos colonizadores incidiu no

ENTRONQUE PATRIARCAL o sea es la forma sistémica de reajustar el patriarcado originario y ancestral que era patriarcado pero no con la intensidad de la violencia del patriarcado europeo, que pero al entroncarse estos dos patriarcado se crean pactos entre hombres que luego van a significar que los cuerpos de las mujeres indígenas, nuestras abuelas y abuelas de nuestros hermanos, resultan soportando todo el

\footnotetext{
${ }^{8}$ Enfatizamos que no patriarcado não basta apenas ser do sexo masculino é preciso comporta-se como um homem com todas as características que o represente como tal, por exemplo: ser hétero.
} 
peso del nuevo patriarcado moderno con su violencia y violación de los cuerpos de mujeres triple y cuadruplemente ejecutados (Paredes, 2011, p. 5).

Destacamos que os corpos de mulheres foram oprimidos de formas distintas. No caso da mulher branca recai sobre seu corpo a opressão de gênero, mas no que diz respeito às mulheres índias e negras estas sofriam/sofrem as opressões decorridas da origem de raça, de etnia, de gênero, de classe e de território (Delgado; Franco, 2014). Desta forma, o patriarcado não se manifesta de maneira linear sobre as mulheres, reconfigurando-se nas relações de poder entrelaçadas por questões de origem, já mencionadas. Por isso o patriarcado é multifacetado tanto na sua origem (entroncamento) como na sua manifestação na sociedade.

Estas formas de opressão sobre as mulheres permanecem celebrando o mito de superioridade do homem. Paredes (2011) enfatiza que o patriarcado colonial/moderno é um sistema de morte construído historicamente sobre o corpo das mulheres. Este engloba costumes, tradições, normas, hábitos, ideias, símbolos, leis, entre outros, e determina, naturaliza e universaliza papéis e lugares das populações, das mulheres e dos homens em diferentes tempos e lugares. Nessa direção, Saffioti aponta que

a identidade social da mulher, assim como a do homem, é construída através da atribuição de distintos papéis, que a sociedade espera ver cumpridos pelas diferentes categorias de sexo. A sociedade delimita, com bastante precisão, os campos em que pode operar a mulher, da mesma forma como escolhe os terrenos em que pode atuar o homem (1987, p. 8).

Percebemos que há uma relação intrínseca entre a constituição da identidade da mulher e da identidade do homem; contudo, essa relação é assimétrica, pois no patriarcado a mulher é considerada como outro, ou seja, a exterioridade do homem, portanto, inferior. Essa atribuição de papéis e lugares é demarcada por um processo que localiza tanto as mulheres quanto os homens dentro de uma pretensa naturalidade. É natural as mulheres pertencerem ao espaço doméstico (reprodução), tanto quanto é natural aos homens serem identificados com o espaço público (produção). Sobre isso, Saffioti diz que

a sociedade investe muito na naturalização deste processo. Isto é, tenta fazer crer que à atribuição do espaço doméstico a mulher decorre de sua capacidade de ser mãe. De acordo com este pensamento, é natural que a mulher se dedique aos afazeres domésticos, aí compreendida a 
socialização dos filhos, como é natural sua capacidade de conceber e dar à luz (1987, p. 9).

A divisão do espaço doméstico tido como naturalmente feminino e do espaço público concebido como masculino estabeleceu uma separação e hierarquia entre a vida privada e a vida pública. Matos e Paradis (2014, p. 66) afirmam que "aos homens, seres imaginados como racionais por excelência, foi dado o direito de consentirem em participar da esfera pública, igualitária e livre. As mulheres, vistas como carentes de razão, deveriam permanecer no lugar que lhes seria 'natural': a esfera privada". Uma das formas de socialização e conformação dessas identidades é através da educação escolarizada via currículos colonizados ${ }^{9}$, portanto, patriarcais-racistas-capitalistas.

Assinalamos que os processos de socialização e manutenção de modos de ser mulher e de ser homem não acontecem de forma simétrica. Todavia o patriarcado colonial-moderno atinge a todas/os, mas de formas e de intensidade distintas condizentes com o contexto histórico, cultural, social, político e econômico, tais como as diferenças raciais, étnicas, de classe, de território e de sexualidade. Paredes adverte que

el Patriarcado, se recicla y se nutre de los cambios sociales y revolucionarios de esta misma humanidad. Afina sus tentáculos, corrige sus formas brutales de operar y relanza las opresiones con instrumentos cada vez mas sutiles y difíciles de detectar y responder (2011, p. 6).

A partir de meados da década de 1980 houve o fortalecimento dos movimentos sociais, dentre estes o Feminista, que proclamava a urgência de mudanças estruturais em que fossem suprimidas as opressões que recaiam sobre as mulheres. Nesse cenário de reivindicações, o patriarcado reinventa-se no intuito de frear as demandas evidenciadas pelos Movimentos Feministas. Para tanto, o patriarcado colonial/moderno se atrela ao neoliberalismo, utilizando-se da institucionalização dos movimentos sociais, visando despolitizar os Movimentos Feministas na luta por libertação das opressões sofridas. Parades (2011) defende que a institucionalização dos Movimentos Feministas possui como uma de suas características os processos de cooptação de mulheres feministas para assumirem cargos estatais e dentro das Organizações não governamentais (ONG), o que, em certa medida, enfraqueceu e desarticulou os Movimentos Feministas.

\footnotetext{
${ }^{9}$ Sobre esse assunto ver Ferreira e Silva, 2014.
} 
Paredes (2011) situa que sob o lema do "empoderamento" das mulheres latinoamericanas que se daria através do acesso ao mercado de trabalho, as ONG oferecem cursos técnicos para estas mulheres, e isto é visto como um ato revolucionário. No entanto, a incorporação das mulheres latino-americanas ao mercado de trabalho é desigual, uma vez que as desigualdades não se restringem à relação opressora entre mulheres e homens. Por exemplo, quando as mulheres ocupam os mesmos cargos que os homens, mas seus salários são menores e se essas mulheres forem negras, indígenas, empobrecidas e lésbicas, dificilmente chegarão a cargos tidos de prestígio e mesmo quando chegam, ainda, podem ser subalternizadas. Para Saffioti,

é de extrema importância compreender como a naturalização dos processos socioculturais de discriminação contra a mulher e outras categorias sociais constitui o caminho mais fácil e curto para legitimar a "superioridade" dos homens, assim como a dos brancos, a dos heterossexuais, a dos ricos (1987, p. 11).

Em nossa acepção, é fundante desvelar os processos de naturalização da condição das mulheres como inferiores aos homens, haja vista que as diferenças não estão restritas à diferença de gênero, mas ainda podemos citar as diferenças intragênero (mulhermulher; homem-homem). As diferenças de raça, etnia, classe e território interseccionadas às relações decorrentes das diferenças intragênero produz relações de poder desiguais sustentadas na racialização da sociedade. Em relação a essa discussão, Saffioti assinala que

a sociedade não está dividida entre homens dominadores de um lado e mulheres subordinadas de outro. Há homens que dominam outros homens, mulheres que dominam outras mulheres e mulheres que dominam homens. Isto equivale a dizer que o patriarcado, sistema de relações sociais que garante a subordinação da mulher ao homem, não constitui o único princípio estruturador da sociedade brasileira (1987, p. 16).

Desse modo, a articulação entre patriarcado-racismo-capitalismo na manutenção e na socialização do sistema mundo patriarcal-colonial-moderno/capitalista constitui a face da mesma moeda. Na discussão sobre o patriarcado Margarita Pisano assinala que

lo que el patriarcado trajo como esencia desde su lógica de dominación la conquista, la lucha, el sometimiento por la fuerza-, hoy se ha modernizado en una masculinidad neoliberal y globalizada que controla, vigila y sanciona igual que siempre. Pero esta vez a través de un discurso retorcido, menos desentrañable y en aparente diálogo con la sociedad en su conjunto, donde va recuperando, funcionalizando, fraccionando, 
absorbiendo e invisibilizando a sus oponentes y que trae consigo una misoginia más profunda, escondida y devastadora que la del viejo sistema patriarcal (2004, p. 10).

A autora chama a atenção de que o patriarcado com o passar dos anos foi reconfigurando-se através das mudanças sociais, políticas e econômicas, ao mesmo tempo em que os Movimentos Sociais Feministas obtiveram conquistas em vários âmbitos da sociedade. Nesse cenário, o patriarcado foi se ajustando às prerrogativas das lutas sociais feministas de forma a camuflar sua opressão, ao criar uma falsa ideia de igualdade entre os gêneros.

Matos e Paradis sublinham que atualmente vivenciamos um patriarcado contemporâneo. Contudo, as autoras ressaltam que "a diversidade da história ocidental das posições políticas das mulheres, em permanente contextualização, transformação e de contradições, dificilmente pode ser remetida à exclusividade da ideia unitária ou totalizante de um único patriarcado" (2014, p. 69).

Nessa perspectiva, frisamos a impossibilidade de homogeneizar apenas uma noção de patriarcado, uma vez que os saberes são sempre localizados (Haraway, 1995) e, portanto, engendram múltiplas faces da patriarcalização e da despatriarcalização. Matos e Paradis (2014, p. 71) defendem a despatriarcalização do Estado como uma maneira de "conduzir e produzir orquestradamente estratégias e mecanismos de descolonização patriarcal e racial do Estado brasileiro e da sua forma de gestão pública, com vistas a reforçar uma nova etapa que tenha foco na conquista de resultados cívicos de políticas públicas". Os movimentos feministas estão trilhando um caminho em busca da despatriarcalização do Estado através da ocupação dos espaços políticos e das lutas por formulações de políticas públicas que primem pela igualdade para as mulheres, sem que sejam desconsideradas as diferenças intragênero.

A partir da compreensão do patriarcado enquanto um sistema de dominação, apresentaremos na próxima seção como o enxergamos na constituição do processo de colonialismo e colonização da Abya Yala e ainda presente por meio das heranças coloniais. 


\section{0 processo de colonialismo e a instauração das hierarquias e subalternizações alicerçadas no patriarcado-colonial-moderno: uma visão dos Estudos Pós- coloniais e do Feminismo Latino-americano}

Nesta seção abordamos a constituição do processo de colonialismo da América Latina, focando as formas de subalternização e de resistências dos povos originários e dos povos africanos ao imperialismo colonial-moderno. Para esse fim utilizaremos conceitos caros aos Estudos Pós-coloniais e ao Feminismo Latino-americano.

A invasão das terras da Abya Yala realizada pelos portugueses e espanhóis, em meados do século XV, resultou na instauração de um modelo de sociedade colonial/moderno/patriarcal que ocorreu por meio do assassinato, estupro de mulheres e exploração de mulheres e homens dos povos originários (aztecas, mayas, chimús, aymaras, incas, chibchas etc.) e posteriormente de mulheres e homens dos povos sequestrados da África (Angolas, Mondongos, Congos, Yolofos, Minas, Lucumíes, Yorubas, Chambas, Guanguís, Carabalíes, Bambaras e Mandingas etc.).

Através deste modelo de sociedade foi possível inventar a América e a Europa, sendo a primeira um apêndice da segunda, tendo em vista que com o "descobrimento" do "novo mundo" os europeus logo tornaram as terras da Abya Yala sua propriedade. Tudo que existia nestas terras passa a pertencer ao homem (branco, burguês, cristão, heterossexual, masculino), ou seja, os bens naturais, os povos originários que foram convertidos em seres sem alma e por isto necessitavam de conversão que só este homem poderia lhes conceder. Silva destaca que

O OUTRO é instituído enquanto o anti-modelo que não possui as condições de ser, de produzir e de viver civilizadamente sem a ajuda (favor) DAQUELE que É. O OUTRO vive a condição de empréstimo, ao não ser e não ter, somente cabendo-LHE reconhecerse como o NÃO-SER e obedecer $\grave{Q} U E L E$ que $E$ (2014, p. 206)

Assim, as mulheres que constituíam os povos originários e, posteriormente, aquelas advindas da diáspora africana foram tomadas como território de conquista do homem (branco, europeu, heterossexual, burguês e cristão), uma vez que seus corpos estiveram associados ao natural e por isto aptos a ser explorados, juntamente com a 
natureza. Estas mulheres foram concebidas enquanto não sujeitos, pois sua humanidade foi negada.

A invasão das "novas" terras e o contato com os nativos foi espaço/tempo para a constituição e a difusão da racionalidade moderna-eurocêntrica-masculinaheterossexual-patriarcal-cristã. Os portugueses e os espanhóis subjugaram as sociedades e as culturas já existentes no que hoje tem por nome América. Esta invasão instalou e determinou uma organização social, cultural, política, econômica e educacional de exploração e de dominação sobre os povos que ali estavam e dos que mais tarde foram escravizados na África e levados para a Abya Yala.

Esta invasão aconteceu de forma desigual, tendo em vista que os autodenominados europeus negaram o modo de organização sócio-histórica, política, epistêmica, cultural e educacional dos povos nativos. E não só isso, as sociedades nativas foram submetidas aos moldes eurocentrados de organização social, pautados no patriarcado europeu. A disparidade entre as formas de organização sócio-histórica, política, epistêmica, cultural e educacional dos nativos em relação às dos europeus, impôs aos povos da Abya Yala a condição de desorganizados, irracionais, não letrados, atrasados e, por isso, inferiores, selvagens, não civilizados. Sendo assim, foi imposto o modelo de sociedade europeia, por essa se considerar uma sociedade organizada, racional, letrada, portanto, superior, civilizada e ideal (Mignolo, 2005).

A invasão da Abya Yala resultou na implementação arbitrária de uma nova ordem de poder, direta e formal, nomeada de colonialismo, imposta de um povo "soberano", o europeu, sobre os povos inferiorizados. Além disso, este colonialismo espalhou-se por meio da colonização dos povos e das culturas dominadas em toda América e, posteriormente, no mundo. Segundo Quijano (2005), a colonização é uma etapa do colonialismo na qual se dá a imposição de formas de conhecer, de trabalho, de cultura e de educação legitimadas como avançadas e superiores sustentadas por um ideal de sujeito branco, europeu, heterossexual, masculino e cristão.

O autor supracitado ainda compreende que o modelo eurocêntrico de dominação e de exploração, empreendido pelos portugueses e espanhóis com a "descoberta" da Abya Yala, sustenta-se em dois pilares fundamentais: a racionalização e a racialização. 0 primeiro diz respeito à hegemonia dos conhecimentos produzidos pelos europeus e das 
formas de produção, sendo considerados os únicos detentores e legitimadores de epistemologias válidas. Ressaltamos que o segundo dá-se com a construção mental da ideia de raça, que classifica e hierarquiza os povos em raças superiores e inferiores e mais especificamente em: brancos, índios, negros, mestiços e, posteriormente, em amarelos. Esta hierarquização e classificação distribuem lugares e papéis sociais de cada sujeito, grupo social e povo no sistema de dominação/exploração mundial do trabalho.

A ideia de superioridade e inferioridade racial determinou que os povos de raças inferiores (índios, negros, dentre outros) não eram dignos de receber salário, pois não eram tidos como seres humanos e, portanto, poderiam ser explorados. Apenas o homem branco-ser humano poderia receber salário. A racialização do trabalho sobrevive, pois os trabalhos de menor prestígio social e os de menor remuneração geralmente são ocupados por pessoas não-brancas, dentre estas as mulheres. Assim, consideramos que o sistema de dominação/exploração mundial do trabalho possui sua base na racialização da população.

A racialização da população não toma apenas a raça como critério de hierarquização, mas também os gêneros, as sexualidades, os territórios, os conhecimentos. Estes marcadores constituem os diferentes corpos e se interseccionam estabelecendo relações que intensificam as subalternizações, ao mesmo tempo se articulam como resistência a racialização. Nessa linha de pensamento, a interseccionalidade (Crenshaw, 2002) desvela que as mulheres marcadas por intersecções ocupam lugares e funções distintas daquelas que não são marcadas por intersecções, logo questiona a ideia de mulher universal.

Mesmo com a "descolonização" ${ }^{10}$ da América, ao deixar de ser colônia, o padrão mundial de poder eurocêntrico/colonial/moderno/patriarcal/capitalista não findou, permanece até a atualidade. Este encontrou novas formas de travestir-se para conservar a sua dominação. Dessa maneira, o colonialismo deixa como herança a colonialidade que

se funda en la imposición de una clasificación racial/étnica de la población del mundo como piedra angular de dicho patrón de poder y opera en cada uno de los planos, ámbitos y dimensiones, materiales y

\footnotetext{
10 Utilizamos está palavra aspeada por compreendemos que os países colonizados ainda permanecem colonizados e que as relações de poder estabelecidas entre os países centrais e os periféricos ainda celebram e materializam desigualdades, evidenciando novas formas de colonialismo.
} 
subjetivas, de la existencia social cotidiana y a escala societal (Quijano, 2000, p. 342).

Assim, a colonialidade é um processo arbitrário de dominação/exploração no qual o ideário colonial penetra as estruturas sociais tanto na dimensão objetiva quanto na dimensão subjetiva dos povos subjugados. Para Quijano (2005), há três eixos da colonialidade: do poder, do saber e do ser, que são imbricadas entre si. Além desses eixos da colonialidade, Walsh (2008) assinala para a colonialidade da natureza e Lugones (2008) para a colonialidade de gênero.

A colonialidade do poder refere-se à classificação e à hierarquização racial dos povos em inferiores e em superiores, tendo por referência o homem-branco-europeucristão-patriarcal, o que determina a distribuição e o controle do trabalho dos povos subalternizados mundialmente. Atrelada a esta colonialidade, temos a colonialidade do saber que implica na negação e na invalidação dos conhecimentos dos não europeus, em especial, dos conhecimentos das mulheres, pois estas não eram concebidas enquanto seres de razão. Esse eixo da colonialidade legitima uma razão que produz um conhecimento neutro/hegemônico/eurocêntrico/masculino/patriarcal e universal, por isso, válida.

Nessa esteira de pensamento, a colonialidade do saber ao reproduzir e valorizar as estruturas de poder fundadas pelo patriarcado, que valoriza os conhecimentos produzidos pelos homens-brancos, desqualifica-nega os desenvolvidos por mulheres. Carosio (2014) assinala que nos moldes patriarcais as mulheres não são concebidas como seres racionais, logo não possuem razão e, portanto, não seriam capazes de produzir conhecimentos.

Os povos subalternizados são tidos como primitivos, irracionais, iletrados e sem cultura, incapazes de ter epistemologias válidas que produzam conhecimentos verdadeiros. A produção intelectual destes povos é entendida como senso comum; esta definição ratifica a hegemonia dos europeus sobre os povos inferiorizados. Ao determinar o que é senso comum, os europeus estão definindo, simultaneamente, o que é conhecimento científico e autoafirmam o seu poder epistêmico. Diante dessa autoafirmação, os europeus legitimam-se como os civilizados e de cultura letrada, em 
detrimento dos demais povos como não civilizados e de cultura não letrada, tratam de desvalorizar a cultura oral dos povos subalternizados e sua relação com a natureza.

Estas manifestações da colonialidade consolidam-se na colonialidade do ser que denota a internalização da subalternidade do não europeu, que passa a aceitar a imagem do colonizador como sua, ocultando a dominação colonial, o que Freire (1987) denomina da condição do oprimido ${ }^{11}$ enquanto hospedeiro do opressor. Esse eixo da colonialidade nega a condição humana dos povos subalternizados uma vez que esses nunca chegarão a ser europeus, "de esa manera seguimos siendo lo que no somos. Y como resultado no podemos nunca identificar nuestros verdaderos problemas, mucho menos resolverlos, a no ser de una manera parcial y distorsionada" (Quijano, 2005, p. 226). Assim, a colonialidade do ser consolida a condição de não sujeito.

Walsh (2008) assinala para a existência de um quarto eixo, da natureza, que é a divisão binária entre natureza e sociedade decorrente da rejeição das ligações espirituais milenárias entre humanos e natureza. Essa divisão estabeleceu uma relação predatória do homem (moderno civilizado) sobre a natureza, a qual obedece aos anseios do capitalismo. Isso culminou, em certa medida, no rompimento incisivo dos laços espirituais e ancestrais que os povos originários mantinham/mantêm com a natureza.

Destacamos que esta divisão acontece do homem europeu-branco-burguêspatriarcal para com a natureza, visto que este homem é um ser de razão e não pode estar ligado à natureza, já que esta é primitiva e por isso pode ser explorada. Por conta da ligação espiritual e de respeito dos povos originários com a natureza, eles foram considerados primitivos e por tal condição estavam passíveis de exploração.

As mulheres pertencentes aos povos originários foram comparadas à natureza por não possuírem razão, permanecendo no estado infantil mesmo quando atingem a idade "adulta”. Por sua ligação à natureza, estas mulheres não eram tidas como seres de razão, não podendo possuir ou produzir conhecimento. Cabe destacar que as mulheres brancas também eram vistas como seres sem razão em relação homem europeu-branco-burguêspatriarcal, no entanto estas mulheres eram superiores às mulheres indígenas e negras.

11 Sobre a relação entre opressor e oprimido ver Fanon Pele negra máscaras brancas, 2008. 
Lugones (2008) realça que não houve apenas o estabelecimento das hierarquias raciais, mas também a hierarquização de gênero, pois a colonialidade de gênero classificou as mulheres como o gênero inferior. Assim a colonialidade de gênero remete a imposição de um gênero dominante que dita as formas de ser mulher e suas funções dentro da sociedade moderna, negando-a sua humanidade. Assinalamos que ainda permanecemos sob essa herança colonial, que tende a localizar e cristalizar mulheres em papeis e funções sociais que intentam negar a sua racionalidade. Evidentemente que as mulheres, em especial, estão lutando para garantir a efetivação de direitos já conquistados e conquistar novos.

Nesse contexto de dominação, a colonialidade reestrutura e sustenta o poder colonial. Porém, isso não acontece de maneira pacífica, os povos atingidos pela dominação colonial e consequentemente pela colonialidade criam resistências a essa dominação. Nessa direção os povos da Abya Yala resistem a essa dominação ao se organizarem coletivamente para reivindicar o seu lugar como território epistêmico que possui suas heterogeneidades e, sendo assim, possuem dinâmicas sociais, políticas organizativas outras.

Os povos subjugados pela colonialidade resistem à dominação colonial afirmandose como sujeitos de direito, que evidenciam o seu lugar como lócus de enunciação epistemológica, política, cultural e educacional, contrapondo-se aos laços de dominação impostos pelo invasor. Além disso, lutam por "um mundo no qual muitos mundos podem coexistir" (Mignolo, 2008, p. 296).

Mignolo (2011) ressalta que a relação conflitiva entre os "povos civilizados" e os "não civilizados" resulta na constituição da diferença colonial que são as tensões resultantes do contato direto entre duas histórias locais: a dos povos colonizados e a dos colonizadores, esta última tida como hegemônica. Estas tensões são resistências à dominação colonial, visto que os povos subjugados apropriam-se da lógica europeia para dialogar com as culturas dominantes a fim de restituir seus conhecimentos que foram negados e inferiorizados pelos colonizadores. Além disso, quer fraturar a estrutura de dominação colonial e, ao fraturá-la, ganhar espaço para a valorização e a legitimação dos seus conhecimentos. Segundo Mignolo, 
la diferencia colonial crea condiciones para el desarrollo de situaciones dialógicas en las que una enunciación fracturada es representada desde la perspectiva subalterna como una respuesta al discurso y a la perspectiva hegemónica (2011, p. 9).

Contudo, a própria diferença colonial foi tratada pelo poder hegemônico de dominação como diferença cultural na tentativa de ocultar a imposição e a consolidação das relações desiguais de poder, isto é, a colonialidade do poder. Ao resumir a diferença colonial à diferença cultural, o padrão de poder hegemônico eurocêntrico tenta ocultar novamente a sua dominação.

Nesse cenário de lutas por emancipação, "las teorías postcoloniales están construyendo una razón postcolonial como un locus de enunciación diferencial” (Mignolo, 1996, p. 14). A diferença colonial representa o estabelecimento de relações conflitivas e dialógicas de lócus de enunciação. As formas de pensamento e de conhecimentos decorrentes desse contexto de diferença colonial são caracterizadas por tecerem resistências propositivas em meio ao contexto de dominação colonial. Assim sendo, o pensamento de fronteira é a expressão dessas relações. Para Mignolo,

el pensamiento fronterizo es algo más que una enunciación híbrida. Es una enunciación fracturada en situaciones dialógicas que se entrelazan mutuamente con una cosmología territorial y hegemónica (ideología, perspectiva) (2011, p. 9).

0 pensamento de fronteira é o revide epistêmico evocado pelas margens subalternizadas em contraposição à margem colonial. 0 pensamento de fronteira não nega a modernidade europeia, porém, a ressignifica através do seu lócus de enunciação. A luta das mulheres latino-americanas pela condição de sujeitos epistêmicos se faz na tensão entre a produção epistêmica do Feminismo Hegemônico de raiz europeia e norteamericana, ou seja, o Feminismo Latino-americano é produzido nas fronteiras epistêmicas no espaço da diferença colonial.

Mignolo afirma que "el pensamiento fronterizo fuerte surge de los desheredados, del dolor y la fúria de la fractura de sus historias, de sus memorias, de sus subjetividades, de su biografia" (2011, p. 28). É o desvelamento e a construção de formas outras de pensar e de produzir conhecimentos. São formas outras de articular conhecimentos locais com os hegemônicos, através de cosmologias e epistemologias outras. 
0 pensamento de fronteira articula-se à desobediência epistêmica ao desafiar o lócus de enunciação eurocêntrico de produção e de formas de produzir epistemologias. Desobedecer epistemologicamente ao paradigma dominante é valorizar e reconhecer metodologias outras de produção de conhecimentos, tomando como referência as experiências de vida daquelas e daqueles silenciados pelo cânone científico europeu dominante. Por isso, o Feminismo Latino-Americano reivindica que as experiências das mulheres da América Latina sejam as bases da produção do conhecimento sobre os processos de subalternização e silenciamento que sofreram/sofrem em diálogo com os conhecimentos produzidos pelo Feminismo Hegemônico. As feministas latino-americanas não negam a importância das produções do Feminismo Hegemônico, mas a referência epistêmica para compreender as subalternizações impostas às mulheres latinas americanas são as suas próprias experiências tecidas na diferença colonial.

A desobediência epistêmica não nega as bases de produção de conhecimento europeu, porém, considera que estas não são mais a referência na produção de epistemologias. Assim, a desobediência epistêmica propõe a sua própria razão e, com isso, visa uma equidade social e política, na qual os povos possam afirmar-se como sujeitos epistêmicos e o seu lugar como território de enunciação epistêmica, conquistando a sua condição epistêmica.

Desta forma, o Feminismo Latino-Americano é fruto da desobediência epistêmica das mulheres latino-americanas que não aceitam os conhecimentos produzidos pelas mulheres europeias e norte-americanas como suficientes para entender as condições existenciais e as possibilidades de superação da condição de subalternidade e de silenciamento instaurados com o processo de colonialismo.

Nessa direção, desobediência epistêmica pressupõe a opção decolonial que "significa pensar a partir da exterioridade e em uma posição epistêmica subalterna vis-àvis à hegemonia epistêmica que cria, constrói, e rege um exterior a fim de assegurar sua interioridade" (Mignolo, 2008, p. 304). A opção decolonial é fundante para a construção de projetos decoloniais.

Os projetos decoloniais não se encontram prontos; estão sendo forjados através das localidades. Esses projetos não almejam substituir modelos de sociedades e sim coexistirem com os já existentes, porém de uma forma outra que não subalternize os 
povos, ao contrário, que os liberte da dominação do padrão mundial de poder eurocêntrico. Dessa maneira, Walsh afirma que projetos decoloniais são

un proceso y labor que pretenden quebrar, transgredir e intervenir en la matriz colonial aún vigente; crear otras condiciones del poder, saber, ser y vivir; desplazar y transformar el corazón de esta matriz que ha sido el capitalismo, haciendo que la vida asuma el centro encaminando hacia la decolonialidad (2008, p. 150).

Desse modo, os projetos decoloniais caminham para a valorização das identidades que foram subalternizadas, sob a justificativa do desenvolvimento e da democracia universais apregoados pelo projeto moderno de salvação da humanidade. Dessa forma, tais projetos revelam a face oculta da modernidade, ou seja, a colonialidade.

O Feminismo Latino-Americano, por sua vez, é fruto de projetos decoloniais construídos pelas experiências vividas das mulheres localizadas na Abya Yala. Mas também propõe projetos outros de superação das condições herdadas do patriarcado colonial/moderno. Estes projetos decoloniais são consequência da desobediência epistêmica tecida por estas mulheres na diferença colonial presente na América Latina.

Diante da necessidade de romper com a dominação colonial, surge a discussão sobre a interculturalidade que tem se intensificado nos últimos anos dentro dos Movimentos Sociais. Estes entendem a interculturalidade como ferramenta de luta no diálogo conflitivo entre culturas, na reivindicação do direito à diferença.

Os governos neoliberais, sob o forte impacto da onda de valorização da diferença, passam a integrar a interculturalidade no seu discurso dela se apropriando de uma maneira diferente daquela colocada pelos Movimentos Sociais. Esses governos compreendem a interculturalidade como ferramenta de silenciamento das demandas sociais dos povos e grupos sociais marginalizados. Diante desse cenário, Walsh (2008) e Sartorello (2009) apontam que a interculturalidade passa a ser vista em duas perspectivas distintas, porém interligadas à funcional e àquela crítica.

A perspectiva de interculturalidade funcional não intenciona romper com os moldes de dominação eurocêntricos, apenas integra os sujeitos à ordem social vigente, ou seja, ao padrão mundial de poder. Esta perspectiva de interculturalidade tem por objetivo amenizar os conflitos sociais, promovendo uma "emancipação social" limitada aos povos e grupos sociais subalternizados. É limitada no sentido de que os moldes eurocêntricos 
de dominação permanecem quase intactos, adornando uma igualdade social deficiente, que na maioria das vezes apenas alimentam os estereótipos geradores das desigualdades: histórica, social, política, epistemológica e educacional.

Assim, a interculturalidade funcional é a oficialização da diferença pelos governos neoliberais dentro da lógica assistencialista de controle social. Para tanto se utilizam de discursos e ações paliativas que disfarçam a dominação pela qual os povos inferiorizados foram, e ainda são, submetidos. Nesse sentido, a interculturalidade funcional não almeja transformar as estruturas de poder sustentadas pela colonialidade e pelo patriarcado colonial-moderno. Ao contrário, reforça-as e camufla ainda mais as desigualdades por elas estabelecidas.

A perspectiva de interculturalidade crítica se contrapõe à perspectiva funcional, ao questionar o modelo de sociedade constituído pela colonialidade. Esta interculturalidade parte das lutas dos povos subalternizados, que reivindicam formas outras de organização de poder e de participação social igualitária. Nesta ótica, a interculturalidade crítica busca elucidar as relações sociais desiguais, a fim de contribuir para um processo de transformação social que enalteça vozes outras. É entendida como um projeto político que se volta à decolonialidade, a transformação e a criação de sociedades libertas do poderio colonial. Assim, a interculturalidade crítica é estabelecida por meio do diálogo conflitivo entre as diversas culturas. Walsh considera que

la interculturalidad entendida críticamente aún no existe, es algo por construir. Por eso, se entiende como una estrategia, acción y proceso permanentes de relación y negociación entre, en condiciones de respeto, legitimidad, simetría, equidad e igualdad. Pero aún más importante es su entendimiento, construcción y posicionamiento como proyecto político, social, ético y epistémico -de saberes y conocimientos-, que afirma la necesidad de cambiar no sólo las relaciones, sino también las estructuras, condiciones y dispositivos de poder que mantienen la desigualdad, inferiorización, racialización y discriminación (2010, p. 78-79).

A interculturalidade crítica retira a venda colocada pela razão moderna que tem ocultado a sua dominação colonial. A partir dessa compreensão a interculturalidade crítica assinala a urgência de afirmar e de valorizar sujeitos, conhecimentos, modos de vida e sociedades outras, estabelecendo um diálogo conflitivo, em igualdades de direitos e de oportunidades no qual muitos mundos possam dialogar e coexistir em igualdade na diferença. 
Assim sendo, a interculturalidade crítica não deseja apenas o reconhecimento e o respeito das distintas formas de ser e de viver no mundo, também almeja a ruptura da estrutura social de dominação fundada pelo padrão mundial de poder eurocêntrico colonial/moderno/patriarcal. Esta concebe a Educação Escolarizada como um mecanismo de importância para o desenvolvimento de práxis contra-hegemônica, na medida em que se posiciona contra a Educação Escolarizada pautada em uma monocultura que realiza assepsias culturais e epistêmicas, o que resulta na promoção da cultura e do pensamento eurocêntrico. Assim, Candau e Russo ressaltam que

a educação escolar exerceu um papel fundamental, tendo por função difundir e consolidar uma cultura comum de base ocidental e eurocêntrica, silenciando e/ou inviabilizando vozes, saberes, cores, crenças e sensibilidades (2010, p. 154).

Dessa forma, o tratamento depreciativo dado às produções intelectuais e culturais dos grupos marginalizados tem o intuito de ocultar e manter as relações de poder desiguais. Estes grupos têm seus conhecimentos reduzidos a manifestações culturais ou, mais especificamente, folclóricas, negando os loci e os sujeitos de enunciação e de produção epistêmica.

Em contrapartida a estas inferiorizações estabelecidas pelo padrão mundial de poder presente na Educação, os grupos inferiorizados estão simultaneamente construindo resistências. Para tanto estes entendem a Educação como mecanismo de luta para reivindicar a validade dos loci epistêmicos baseada em projetos decoloniais. Nessa linha, os Movimentos Feministas questionam uma educação dual destinada a meninas e meninos, fazendo uma crítica severa ao currículo, ao denunciar os livros didáticos como portadores de estereótipos de gênero.

A Educação intercultural crítica concebida como paradigma educativo outro, materializa-se no fazer pedagógico e este é vivenciado através da práxis política, epistêmica e contra hegemônica. Assim, os processos educativos fundamentados na educação intercultural questionam e desafiam a colonialidade. Portanto, educação é conflitiva ao expressar as relações de poder que interferem no desenvolvimento de processos educativos igualitários.

Além disso, a educação intercultural crítica orienta a pedagogia decolonial. Oliveira e Candau (2010) apreendem esta pedagogia como uma teoria e prática fundadas nas 
insurgências educativas propositivas que desejam a criação e a construção de novas articulações sociais, políticas, culturais e epistêmicas. É uma pedagogia orientada na práxis das lutas dos povos subalternizados que dialogam com seus antecedentes políticos e culturais. Neste sentido, a pedagogia decolonial sustenta-se na interculturalidade crítica ao desafiar a razão moderna, ao assumir a responsabilidade de criação de projetos educativos em que articule a ética, a política, a epistemologia local em consonância com o lugar dos povos subalternizados e em constante confronto com o poder eurocêntrico.

Ressaltamos que o Feminismo Latino-Americano propõe uma pedagogia feminista decolonial. Espinosa Miñoso et al (2013) frisam que esta pedagogia religa corpo e mente, emoção e razão, individualidade e coletividade, que foram separados e hierarquizados pela modernidade, ou seja, pelo paradigma dominante. A religação defendida pela pedagogia feminista decolonial intenta não apenas modificar os discursos como também as práticas pedagógicas que fazem e desfazem dos corpos de mulheres racializadas.

Assim, as mulheres racializadas da Abya Yala apontam para a necessidade de propor concepções de educação que valorizem as complexidades existentes nas várias culturas, tendo em vista que buscam o desenvolvimento de formas organizativas educativas específicas, pressupondo práticas pedagógicas outras.

Por isso é fundamental desvelar a interseccionalidade para que não haja uma homogeneização da condição social e histórica das mulheres, levando a produzir uma falsa ideia de despatriarcalização. Uma vez que o patriarcado atinge todas as mulheres, porém de formas diferentes, por conseguinte a despatriarcalização não acontece da mesma maneira. A vivência da patriarcalização e da despatriarcalização está atrelada às opressões que são interseccionais, gerando assimetrias e ambivalências entre mulheres.

Valdivieso (2014) assegura que na atualidade as ativistas e acadêmicas feministas da Abya Yala têm vivenciado experiências políticas e epistemológicas que visam romper com o modelo de sociedade patriarcal/colonial/moderno. As lutas por igualdades de direitos sociais e políticos básicos, tais como: educação, moradia, trabalho, são lutas constantes das mulheres que tensionam o modelo vigente de sociedade, enquanto as heranças patriarcais sobreviverem os direitos das mulheres não estarão assegurados. 
Nessa direção, o Feminismo Latino-americano vem realizando rachaduras políticas e epistêmicas ao denunciar as formas de exploração e opressão sofridas pelas mulheres indígenas, negras e mestiças pobres da Abya Yala. As Feministas da Abya Yala estão ancoradas em contextos específicos, em corpos e em territórios distintos que constituem contextos sócio-históricos, culturais e políticos em que realizam os seus quefazeres $^{12}$. 0 Feminismo Latino-americano realiza os quefazeres, questionando as configurações históricas e sociais que as localizam na condição de mulheres racializadas. Para tanto, está fundado em uma teoria-prática enraizada nas epistemologias tecidas em suas realidades sócio-históricas.

O revide epistêmico do Feminismo Latino-Americano religa o sujeito de enunciação ao lugar epistêmico, desvelando a colonialidade do saber e a colonialidade de gênero. 0 Feminismo Latino-Americano busca, em suas práticas, romper com o patriarcado colonial/moderno através de lutas contra "el heteropatriarcado, el racismo, la misoginia, la violencia cotidiana dirigida las mujeres racializadas" (Espinosa Miñoso et al., 2013, p. 407). Nesta direção, é notória a importância de considerar o lócus de enunciação das mulheres, tendo em vista que estas mulheres possuem não só as marcas das opressões impostas pelo patriarcado colonial/moderno como também as marcas das resistências que caminham para a descolonização de seus corpos.

\section{Conclusões}

Através do diálogo entre os Estudos Pós-coloniais e o Feminismo Latinoamericano foi possível evidenciarmos as heranças coloniais fundadas no patriarcado colonial-moderno, bem como os movimentos teórico-metodológicos desde o sul global que vislumbram rupturas com o padrão de dominação instaurado desde o processo de colonialismo e que sobrevive através das referidas heranças.

\footnotetext{
${ }^{12}$ Segundo Freire (1987, p. 70), "os homens são seres do quefazer é exatamente porque seu fazer é ação e reflexão. É práxis. É transformação do mundo. E, na razão mesma em que o quefazer é práxis, todo fazer do quefazer tem de ter uma teoria que necessariamente o ilumine. 0 quefazer é teoria e prática".
} 
Destacamos que a cultura patriarcal incide diretamente no controle dos corpos, na construção de subjetividades, na distribuição dos lugares na sociedade de mulheres e homens, estabelecendo hierarquias que geram desigualdades entre os gêneros e intragênero. Contudo, são as mulheres, principalmente, as marcadas por interseccionalidades que tem sofrido de forma mais severa os efeitos do patriarcado colonial-moderno.

Conforme podemos assinalar as heranças coloniais ainda se encontram ativas e interferindo nos processos de emancipação das mulheres, simultaneamente, também há resistências tecidas por distintas mulheres que carregam as suas pautas de luta contra as investidas patriarcais. Nessa direção, entendemos que não há apenas o movimento de opressão, mas também o de resistência que coexistem no espaço da diferença colonial.

Nessa esteira de pensamento as diferenças intragênero constituem este espaço em movimentos ambivalentes e assimétricos. Ambivalentes, pois em determinados momentos as diferentes mulheres se unem de forma monolítica, possibilitando avançar em contraposição às heranças coloniais de forma a somar forças contra o inimigo comum a todas às mulheres, o patriarcado. Assimétricos, uma vez que as diferenças intragênero articuladas à interseccionalidade de opressões distanciam os diferentes grupos de mulheres e revelam relações de opressão e discriminação entre às próprias mulheres. Assim, mulheres brancas da classe favorecida com escolarização possuem maiores chances de rupturas com o patriarcado; enquanto que as mulheres não-brancas da classe popular, com pouca escolarização têm maiores dificuldades de rupturas. Nas encruzilhadas de subalternizações são estas mulheres que sofrem de forma mais violenta o peso das diferenças que constituem seus corpos e que as distanciam de um ideal de ser mulher aos olhos da cultura patriarcal.

Diante do exposto, acentuamos que os movimentos por libertação das heranças imperialistas não acontecem de forma isolada e que os diferentes sujeitos, não só às mulheres, são protagonistas de lutas por libertação do patriarcado colonial-moderno. Assim, olhar para a Abya Yala através de lente teóricas que tomam os sujeitos do sul global enquanto sujeitos de produção e enunciação de epistemologias criar possibilidades de superação das heranças coloniais fundadas no patriarcado. 


\section{Referências}

ARIÈS, Philippe. (1986). História social da criança e da família. Rio de Janeiro: Editora Guanabara

BEAUVOIR, Simone de. (1970). O segundo sexo: fatos e mitos. 4. ed. São Paulo: Difusão europeia do livro.

BRAH, Avtar. (2006). Diferença, diversidade, diferenciação. Cadernos Pagu, Campinas, pp.329-376, janeiro-junho.

CANDAU, Vera Maria Ferrão; RUSSO, Kelly. (2010). Interculturalidade e Educação na América Latina: uma construção plural, original e complexa. Revista Diálogo Educacional. Pontifícia Universidade Católica do Paraná Brasil.

CAROSIO, Alba. (2009). El Feminismo Latinoamericano y su Proyecto Ético-Político en el siglo XXI. Revista Venezolana de Estudios de la Mujer, Caracas, v. 14, n. 33, pp. 13-24. Julio/Diciembre.

CAROSIO, Alba. (2014). Feminismos para un Cambio Civilizatorio. Caracas, Venezuela: CLASCO, 2014.

CRENSHAW, Kimberlé. (2002). Documento para o Encontro de Especialistas em Aspectos da Discriminação Racial relativos ao Gênero. Estudos Feministas, Florianópolis.

ESPINOSA MIÑOSO, Yuderkys et al. (2013). Reflexiones Pedagógicas en torno al Feminismo Descolonial: una conversa en cuatros voces. En: WALSH, Catherine. (Org.). Pedagogías Decoloniales: prácticas insurgentes de resistir, (re)existir y (re)vivir. Série Pensamiento decolonial. Quito, Ecuador: Ediciones Abya-Yala.

FANON, Frantz. (2008). Pele negra, máscaras brancas. Tradução de Renato da Silveira. Salvador: EDUFBA.

FERREIRA, Michele Guerreiro; SILVA, Janssen Felipe da. (2014). Protagonismo dos Movimentos Sociais Negros na superação da herança colonial, nos Currículos Colonizados das escolas brasileiras. Tópicos Educacionais, Recife, n. 1, jan/jun.

FREIRE, Paulo. (1987). Pedagogia do Oprimido. 17. ed. Rio de Janeiro: Paz e Terra.

GROSFOGUEL, Ramón. (2008). Para descolonizar os estudos de economia política e os estudos pós-coloniais: transmodernidade, pensamento de fronteira e colonialidade global. Revista Crítica de Ciências Sociais, n. 80, p. 115-147, Março.

HARAWAY, Donna. (1995). Saberes Localizados: a questão da ciência para o feminismo e o privilégio da perspectiva parcial. Cadernos Pagu, Campinas, pp. 07-41.

INSTITUTO PESQUISA APLICADA. Retrato das Desigualdades de Gênero e Raça - 1995 a 2015. Disponível em: < 
http://www.ipea.gov.br/portal/index.php?option=com_content\&view=article\&id=2952 6> Acesso em: 30 de abril, 2018

LUGONES, María. (2008). Colonialidad y género. Tabula Rasa. Bogotá - Colombia, No.9: 73-101, julio-diciembre.

MATOS, Marlise; PARADIS, Clarisse Goulart. (2014). Desafios à despatriarcalização do Estado brasileiro. Cadernos Pagu, Campinas, n. 43, p. 57-118, jul-dez de 2014.

MIGNOLO, Walter. (1996). Herencias colonialies y teorías postcoloniales. Biblioteca Virtual de Ciencias Sociales. Disponível em: <www.choconautas.edu.pe>. Acesso em: 25 abr. 2012.

MIGNOLO, Walter. (2005). Cambiando las éticas y las políticas del conocimiento: la lógica de la colonialidade y la postcolonialidad imperial. Tabula Rasa, Bogotá, n. 3, enerodiciembre, pp. 47-72.

MIGNOLO, Walter. (2008). Desobediência epistêmica: a opção descolonial e o significado de identidade em política. Cadernos de Letras da UFF - Dossiê: Literatura, língua e identidade. Rio de Janeiro, n. 34, p. 287-324.

MIGNOLO, Walter. (2011). Historias locales/diseños globales: colonialidad, conocimientos subalternos y pensamientos fronterizo. Madrid: Akal.

MOHANTY, Chandra Talpade. (2008). Bajo los ojos de occidente. Academia Feminista y discurso colonial. Artículo publicado en: Liliana Suárez Navaz y Aída Hernández (editoras): Descolonizando el Feminismo: Teorías y Prácticas desde los Márgenes. Madrid: Cátedra.

NARVAZ, Martha Giudice; KOLLER, Sílvia Helena. (2006). Famílias e Patriarcado: da prescrição normativa à subversão criativa. Psicologia \& Sociedade; 18 (1): 49-55; jan/abr.

OLIVEIRA, Luiz Fernandes de; CANDAU, Vera Maria Ferrão. (2010). Pedagogia Decolonial e Educação Antirracista e intercultural no Brasil. Educação em Revista. Belo Horizonte, v. 26, n. 01, p. 15-40, abr.

PAREDES, Julieta. (2010). Hilando Fino desde el feminismo comunitario. La Paz, Mujeres Creando Comunidad.

PAREDES, Julieta. (2011). Una sociedad en estado y con estado despatriarcalizador. Cochabamba, Diciembre.

PISANO, Margarita. (2004). El Triunfo de la Masculinidad. Chile: Surada Ediciones, 2004.

POCAHY, Fernando Altair. (2011). Interseccionalidade e educação: cartografias de uma prática-conceito feminista. Textura, Canoas, n. 23, p. 18-30, jan./jun. 
PORTO-GONÇALVES, Carlos Walter. (2009). Entre América e Abya Yala - tensões de territorialidades. Desenvolvimento e Meio Ambiente, Curitiba, Editora UFPR, n. 20, p. 2530, jul./dez.

QUIJANO, Aníbal. (2000). Colonialidad del Poder y Clasificacion social. In:

WALLERSTEIN, Immanuel. Journal of world systems research. California, v. 2.

QUIJANO, Aníbal. (2005). Colonialidade do Poder. In: LANDER, Edgar (Org.). A

Colonialidade do Saber: eurocentrismo e Ciências sociais. Perspectivas latino-americanas.

Colección Sur, CLACSO, Ciudad Autónoma de Buenos Aires, Argentina. Siembro.

SAFFIOTI, Heleieth. (1987). O poder do macho. São Paulo: Moderna.

SAFFIOTI, Heleieth. (2015). Gênero Patriarcado Violência. São Paulo: Expressão Popular.

SANTOS, Boaventura de Sousa. (2008). Um discurso sobre as ciências. São Paulo: Cortez.

SARTORELLO, Stefano Claudio. (2009). Una perspectiva crítica sobre interculturalidade y educación intercultural bilingüe: El caso de laUnión de Maestros de la Nueva Educación para México (UNEM) y educadores independientes en Chiapas. Revista Latinoamericana de Educación Inclusiva, Santiago de Chile.

SILVA, Janssen Felipe da. (2015). Sentidos de Avaliação da Educação e no Ensino e no Currículo na Educação Básica através dos Estudos Pós-Coloniais Latino-Americanos. Espaço Do Currículo, v. 8, n. 1, p. 49-64, Janeiro a Abril de.

SILVA, Janssen Felipe da. (2014). Sentidos da Educação na Perspectiva dos estudos póscoloniais latino-americanos. In. MARTINS, Paulo Henrique; SILVA, Marcos de Araújo; LIRA, Bruno Freire; LEÃO, Éder Lira de Souza; (et al). Guía sobre post-desarrolo y nuevos horizontes utópicos. Ciudad Autónoma de Buenos Aires: Estudios Sociológicos Editora, 2014.

SILVERBLATT, Irene. (1990). Luna, sol y brujas. Género y clases en los Andes prehispánicos y coloniales. Cusco: Centro de Estudios Regionales Andinos "Bartolomé de Las Casas".

VALDIVIESO, Magdalena. (2014). Otros tiempos y otros feminismos en América Latina y el Caribe. In: CAROSIO, Alba. Feminismos para un Cambio Civilizatorio. Caracas,

Venezuela: CLASCO.

WALSH, Catherine. (2008). Interculturalidad, plurinacionalidad y decolonialidad: las insurgências politico-epistémicas de refundar el Estado. Tabula Rasa, Bogotá, n. 9, 2008.

WALSH, Catherine. (2010). Interculturalidad crítica y educación intercultural. In: VIAÑA, Jorge; TAPIA, Luis; WALSH, Catherine. Construyendo Interculturalidad Crítica. 3. ed. La Paz, Bolivia: CAB Instituto Internacional de Integración del Convenio Andrés Bello. 